\title{
The Global Eye or Foucault Rewired: Security, Control, and Scholarship in the Twenty-first Century
}

The great antagonist in J.R.R. Tolkien's Lord of the Rings, Sauron, is metonymically described in the novel and visualized in Peter Jackson's cinematic trilogy as the 'great eye.' The 'Eye of Sauron,' the 'red eye,' and the 'great eye' are epithets that arguably connote an embodied feeling to the penultimate villain in Tolkien's trilogy. This is reported in a letter sent by Tolkien to his friend Mrs. Eileen Elgar on October 3, 1963: “[...] in a tale which allows the incarnation of great spirits in a physical and destructible form their power must be far greater when actually physically present. [...] Sauron should be thought of as very terrible" (Carpenter 1981, 246). Throughout the saga, the thought of Sauron trumps the character's materiality. Sauron is less an active driver of antagonistic action than he is a sensation of danger and fear. He is less a character than an ambiance conveyed through the terror of pervasive, continuous, absolute, and totalitarian observation.

The Lord of the Rings trilogy, written roughly between 1937 and 1949, substantiates, in Sauron's eye, a particular twentieth-century panopticophobia: the fear of universal control via sight, at a time when the tools to expand the capacity for control over populations were starting to grow exponentially. As the century unfurled, visual control widened and became pervasive, from the improvement of weapon target accuracy via optics, to the introduction of visual technologies in the public sphere. ${ }^{1}$ In fact, the very project of modernity in its dual dimension of progress on the one side, and violent exploitation on the other, is a by-product of the Enlightenment project equating the progress of reason to the widening of a politically controlled system of images. If anything is common to the projects of late and early modernity, it is the organization around plans of total visuality. They encompass simultaneously utter control and utter sight, defined by Nicolas Mirzoeff as the mandate to see and control everything, everywhere, all the time (Mirzoeff 2015, 20). This plan of total visuality hence becomes a strategic driver in the organization of the social and in the partition of the sensible, as well as an overhaul in the wider production of meaning. As such, a twenty-first-century agenda for the study of culture will unavoidably deal with visuality beyond modes of mediation and representation to ask how and under which conditions the pro-

1 On modernity and vision, see Paul Virilio 2009 as well as Jonathan Crary 1999.

Ә Open Access. (C) 2020 Isabel Capeloa Gil, published by De Gruyter. (c) BY-Nc-ND This work is licensed under a Creative Commons Attribution-NonCommercial-NoDerivatives 4.0 International License. 
duction of meaning is shaped by technologically induced visual surveillance. The gathering of visual data, the visual control, taps into what Yuval Noah Harari has termed the algorithmic hacking of humanity (Harari 2018, 308). It changes the way in which cultural subjects look at the world and make sense of it, going all the way deep into the very sense of social and political subjectivity, and rebooting the wider understanding of culture as the practices, discourses, and products that aggregate the way in which humans interact with each other and the world around them.

And yet, Sauron and even Orwell's 'Big Brother' speak to a different world, a world of centralized and unified surveillance, of vertical linear power structures, a pre-modern panoptical world in fact, clearly identified by Michel Foucault in his reading of Jeremy Bentham's panopticon. Under twenty-first century conditions, the control system of technical vision is multipolar, diffuse, overarching, and overwhelming, cutting across all human action from biometric identification to smart phones, personal computers to CCCR cameras at airports, playgrounds, schools, churches, restaurants, and in the public space. From the practice of facial recognition effective now in China (Fig. 1) to body scanners at airports, the project of visual domination acts to produce a transparent body, stripped of its opaque singularity. ${ }^{2}$

Despite a semblance of democratic empowerment, because all that are seen are apparently also agents of seeing, the system of images that structures late modernity, and the resulting explosion of control centers across multiple, diffuse, and diverse sight points, is consistently built upon a few centers of dominance. These range from national security agencies to private surveillance providers, from media conglomerates to the entertainment industry, and even from the influencer's Instagram page to the structured streaming of images by social media platforms, from Facebook to Instagram, Twitter, and YouTube. Beyond the containment of the dangerous in the correction institutions (prisons, reformatories, hospitals, and asylums), the control of the stream of produced images has become a privileged tool: to manage those who see, but also limiting access and thereby influence; regulating, monitoring, and restraining. The control of visual regimes, whether made visible or invisible, has shaped modernity's "structure of feeling” (Williams 1961).

As such, it has unavoidably impacted the production of scholarly research particularly in the humanities, as it articulates questions of democratic access and inclusion (Appadurai 2006), and of citizenship (Azoulay 2008) crafted by an

2 See on body scanners, the forthcoming work by Ilios Willemars. The Body as Placeholder: Incorporated Subjects in Digital Art. 
understanding that the right to see is melded with the right to be seen and heard by the State. But it also connotes the anxiety over technological transformation (Turkle 2009), over the future of the human subject, and the right to privacy and embodiment (Scott 1998; Chamayou 2011). The transparent body under surveillance equates to the subsumption of flesh to numerical abstraction. The utopia of vision as empowered access to knowledge that inspired the metaphor of sight for the European Enlightenment oozes into A.I.-powered smartglasses for facial recognition (Fig. 2) materializing the dystopia of global snooping and algorithmic control via visualization in countries like China (Mozur 2018).

While surveillance, following the rising interest in security and terrorism, has given vent to prolific scholarly production, not least following the studies inaugurated by David Lyon (Lyon 1994) and William Staples (Staples 1997), the hermeneutical toolbox of cultural studies reveals ample possibilities in the exploration of the crossover between the regimes of the visual and technologies that structure them, among them the visual arts, film, and literature. And then, as Lawrence Grossberg argues, it is our task to question the context (Grossberg 2010), widening the field to explore the (in)visible conditions that structure the project of total visibility and its impact in shaping late modernity's forms of subjectivity, ways of belonging, communicating, and living.

\section{The Terror of Sight}

In Western iconology, the sense of sight ${ }^{3}$ has traditionally symbolized knowledge and/as control, be it over the body (as in Aristotle), ${ }^{4}$ the city (the sovereign eye), or the world (the eye of God). Pre-modern approaches to sight connote both a creative dimension - as in Nicholas of Cusa, De Visione Dei - and a phobic, terrifying side, epitomized in the frightening stare depicted, for instance, in Caravaggio's famous rendering of the Gorgo or Medusa (1597).

3 Sight is understood as a multimodal category in the arguments presented by Jonathan Crary in Suspensions of Perception, which define it as a historically situated and culturally constructed category that is irreducibly a mixed multisensorial modality, encompassing touch, hearing, taste, and smell, Crary 1999, 3.

4 In Metaphysics, Aristotle writes: "All men by nature desire to know. An indication of this is the delight we take in our senses; for even apart from their usefulness they are loved for themselves; and above all others the sense of sight. For not only with a view to action, but even when we are not going to do anything, we prefer seeing (one might say) to everything else. The reason is that this, most of all the senses, makes us know and brings to light many differences between things" (Aristotle 1999, I, 1, 980a 21-26). 
In 1453, Nicholas of Cusa anthropocized the idea of God's vision and represented divine sight as embodied and culturally situated perception. In chapter two of his De Visione Dei, titled “Absolute Sight encompasses all modes of seeing," he wrote that:

Notice that in those who have sight, sight varies as a result of the variety of its contracted-
ness. For our sight is conditioned by the affections of the organ and of the mind. [...] But
sight that is free from all contractedness [...] encompasses at one and the same time each
and every mode of seeing. For without Absolute Sight there cannot be contracted sight. But
Absolute Sight encompasses all forms of seeing - encompasses all modes in such a way that
it encompasses each mode. And it remains all together free from all variation. For in Abso-
lute Sight every contracted mode of seeing is present uncontractedly.
(Cusa 1999, 683)

For Nicholas of Cusa, seeing is not a natural given, but a situated multisensory endeavor. He distinguishes between individual sight that is both varied and limited, and the Absolute Sight that overcomes "contractedness" as it encompasses all forms of seeing. The above excerpt suggests the difference between finite vision and the infinite spherical vision of God, which is nonetheless modeled after human experience. Written to accompany a visual experiment, the text instructs the monks of Tegernsee to circumambulate an all-seeing icon of God. Developing the concept of infinite space that had found a geometrical representation in the vanishing point, ${ }^{5}$ Cusa places it within God's eye, which retains its medieval and religious function by gazing out of the painting at the monk according to inverse perspective. As Arianne Conty writes, Cusa constructs a veritable sociology of belief, in which believing the word of the other, of the community, is necessary for each individual's understanding of God (Conty 2012, 480-481). In this sense, there can be no unmediated experience of the divine, for God, as infinite and absolute, cannot be reduced to a single perspective. Cusa's experiment suggests that individual seeing is an unreliable source for communal belonging, because what we see cannot be shared. However, one can share the trust in the vision of God conveyed by the Scripture, which thus overcomes singularity and beacons to universal meaning.

God's vision, hence, organizes a system of dependence of the diverse and limited upon the unlimited central and omnipresent Eye of God as it presents a system of power that though unseen is clearly located at the idealized heart/ center of the universe. The Eye of God is the vanishing point of a universe continuously observed and controlled by the transcendent.

A different strand is invoked by the trope of the Gorgo. The Medusa, here depicted in Caravaggio's famous painting, the Gorgon slain by Perseus, is the

5 The geometrical perspective was developed by Filippo Brunelleschi in Florence in 1413. 
epitome of seeing as trauma and panic (Fig. 3). Let us consider for a moment the story of the Gorgon. ${ }^{6}$ Medusa shares with her sisters Stheno and Euryale a terrifying appearance. These monsters with snake hair were said to possess huge teeth and a beard, in addition to a powerful shrieking voice, and a gaze that turned all those who beheld them into stone. Medusa (also Médusa, the 'Lady,' Gil 2007, 329), unlike her kin, was mortal. That is why Perseus, in order to save the young Andromeda, and aided by the goddess Athena, could resort to trickery to approach the beast and capture her head. Cloaked in a cape that rendered him invisible and armed with a mirror, Perseus approached the monster in arrears, guiding his moves with the aid of the mirrored reflection. When the Gorgo's gaze hit the mirror, she saw her own reflection, hence turning herself to stone. The Medusa presents the phobia of the gaze, the horror of perception in a world marked by catastrophe and frozen to stone by the panic of seeing. As a metaphor of the observer, the monstrous body of the Medusa presents the dislocation of the spectator from the order of things. Medusa's glaring eyes and guttural cry present in Italian philosopher Adriana Cavarero's words the "human appalled by his very being and contemplating the unspeakable act of his own annihilation" (Cavarero 2005, 25).

The double logic of creation and terror, of producing a subjectivity within a logic of terrifying control, precisely to limit the possibilities of the controlled subject to unleash that very same terror (be it the plague or crime), is what lies at the node of the Foucauldian surveillance model, inspired by Jeremy Bentham's model of the panopticon. Foucault's work has inspired social theory along the past 40 years, interested as it was in understanding the complex modulations of power in its articulation with disciplinary technologies and the very institutions of modernity (the prison, the factory, the hospital, the school, the church, the court) and how they impacted the production of subjectivity. Bentham's panopticon is an enlightening trope in this strategy of control that brings about a radical paradigmatic shift in the production of modern subjectivity.

Hence the major effect of the Panopticon: to induce in the inmate a state of conscious and permanent visibility that assures the automatic functioning of power. So to arrange things that the surveillance is permanent in its effects, even if it is discontinuous in its action; that the perfection of power should tend to render its actual exercise unnecessary; that this architectural apparatus should be a machine for creating and sustaining a power relation independent of the person who exercises it; in short, that the inmates should be caught up in a power situation of which they are themselves the bearers. To achieve this, it is at once too much and too little that the prisoner should be constantly observed by an inspector: too little, for what matters is that he knows himself to be observed; too much,

6 On the duplicity of the Medusa, see Vernant 1985; Gil 2007. 
because he has no need in fact of being so. In view of this, Bentham laid down the princi-
ple that power should be visible and unverifiable. Visible: the inmate will constantly
have before his eyes the tall outline of the central tower from which he is spied upon.
Unverifiable: the inmate must never know whether he is being looked at at any one
moment; but he must be sure that he may always be so. [...]
The Panopticon is a / machine for dissociating the see/being seen dyad: in the peripheric
ring, one is totally seen, without ever seeing; in the central tower, one sees everything
without ever being seen.
(Foucault 1975, 201-202; my emphasis)

The importance of the panopticon is to produce a permanent visibility-inducing machine that becomes the hallmark of modern power, structured upon the ability to dissociate this ever present and all-seeing entity from the seen. That is, hiding agency, the voyeuristic machine of vision produces subjectivities structured on utter control and transparency, because in the Foucauldian conditions of high modernity, though power is unverifiable, it is utterly visible. Foucault's reading of Bentham's pedagogical panopticon has effectively not only given vent to a wide array of studies on the trials and mechanisms of what David Lyon in 1994 named "surveillance society" (Lyon 1994), but arguably has fielded a new culture as well, a culture of surveillance, creatively producing surveyed subjectivities (Staples 1997). This culture has impacted scholarship and created a new sub-field of surveillance studies, situated on the cusp of politics and interpretation, philosophy and sociology, technology and the humanities.

\section{The Culture of Visual Surveillance and Scholarship in the Humanities}

The conditions under which the technologies of surveillance operate in the post 9/11 world have changed. Not only does the center no longer hold, but the directions, the flows, and the locations from which the panoptic control is exercised have multiplied and changed. Whereas the panopticon, in Bentham's assertion and Foucault's reading of Bentham, rests on the potential visibility of the observer and on the sheer and radical stability of the position from which power is exercised, in the post 9/11 world, power is still unverifiable and permanent, but it is utterly invisible, exercised from a multiplicity of even contradictory positions. The post 9/11 culture of surveillance is best epitomized in a global eye, made up of multiple smaller eyes, that exert power in what Arjun Appadurai calls a "volatile morphing” (Appadurai 2006, 83), of reciprocal and contradictory observation, a control spreading rapidly over the globally networked 4.0 industry. The volatility, and the multiple and multidirectional seeing positions, conflate a social 
technological drive that radical critics, such as William Staples in The Culture of Surveillance, have called the visual "pornography" of total self-display (Staples 1997). Display and technologically mediated self-presentation become extraordinarily effective modes of self-surveillance.

James C. Scott's remarkable Seeing Like a State (1998) insightfully places the operation of the state at the center of the transformations in the conflation of knowledge, vision, and control. Scott's research shows how state power and the modern project is not simply a project of absolute visibility, but of restricting access to vision and of constraining the right to look, exerted through forms of rationalization and simplification.

Certain forms of knowledge and control require a narrowing of vision. The great advantage of such tunnel vision is that it brings into sharp focus certain limited aspects of an otherwise far more complex and unwieldy reality. This very simplification, in turn, makes the phenomenon at the center of the field of vision more legible and hence more susceptible to careful measurement and calculation. Combined with similar observations, an overall, aggregate, synoptic view of a selective reality is achieved, making possible a high degree of schematic knowledge, control, and manipulation.

(Scott 1998, 11)

As the new vanishing point of secular modernity, the state thus enacts a model of control that rests on the expansion of technological capacity - to see everything, everywhere, everytime - but also on the concomitant narrow selection of visual data, that leads in turn to a simplification ultimately aimed at making the phenomenon more legible, but also more schematic and prone to manipulation. Suggestively, Scott's diagnosis of simplified legibility opens up the field for a scholarly questioning of the project from the perspective of a counter-legibility, enacted on the intersection of the visible and the visual with the textual and the speakable, inviting complexity, where simplification is becoming the rule.

In liquid modernity, the panopticon that organized the populations with the ultimate end of keeping in, in gated areas, the undesirable, damaged, sick and dysfunctional parts of society, has given way to a different logic. As Zygmunt Bauman argued, in the new post-panoptic society, the surveillance dispositif is creative of subjectivities that are not simply produced from the standpoint of a general dominating entity, but it is fragmented and heterogeneous. ${ }^{7}$ It operates through state and corporate entities and it reflects

7 Post-panoptic developments have been studied by scholars such as David Lyon, proposing the synopticon as a technology mediated device of permanent observation, Lyon 2006, 35, or Didier Bigo 2011, proposing the term ban-opticon to define the way in which profiling technologies are used to create surveilled and excluded identities; see Bauman and Lyon 2013. 
[...] a more general phenomenon of surveillance philosophy and surveilling equipment wrapped around the task of 'keeping away' instead of 'keeping in', as the panopticon did, and drawing its life juices and developmental energy from the currently unstoppable rise of securitarian preoccupations, not from the disciplining urge as in the case of the panopticon.

(Bauman and Lyon 2013, 58)

If the age of the (post) panopticon in its steady and heavy institutional sense is over, as Jean Baudrillard (1994) announced in Simulacra and Simulation, and has been substituted by pure representation, a world of simulacra meaning nothing but themselves, what societies have experienced is the effective tightening of social control through volatile abstraction (refugees as swarms, the migrant caravans, etc.), eliciting a radical transformation in surveillance modes. They have changed to become more pervasive, permanent, lighter, faster, and increasingly supporting preemptive action. Having dissociated, in Foucault's terms, the seeing from the seen, the global surveillance eye enacts a seeing ex-ante, even before there is anything to be seen. One of the most remarkable examples of this evolution is the drone, be it the civilian gadget form that hovers over malls and parks, and that is consistently pushed as the new trendy object of consumption in airport tax-free shops all over the globe, or in its military form as the UAV or $\mathrm{UCAV},{ }^{8}$ potentiating the pervasiveness of an unseen repressive and murderous power machine.

In its military form, the drone captures the imagination, just as it is a product of a heritage of cultural representations of phobia. Naming is an act of power. Named the Reaper, the Predator, or the Gorgo, the UCAVs capture the imagination of fear and project the drone controller's imagination of power and control over a vision of society and culture. The wrong attire in the wrong place, a children's game that falls outside the scope of the cultural understanding of the observer, a gesture out of hand, a social gathering outside the pattern of Western sociality, may trigger a click with deadly impact. What goes on in the command room at Creech Air Force Base in Nevada, where the US Air Force's drone squadron operating in Afghanistan is located, and in other military sites engaged in the 'war from a distance' and in cyberwar, is not simply a matter for politics, military sciences, and social studies. This is a matter of culture, a second wave of surveillance studies in which we who partake in meaning-making activities must engage.

One of the most remarkable studies of the cultural implications of the age of the drone, Grégoire Chamayou's Drone Theory (2011), argues that in the new stage of the war on terror, precisely the business of detection and preemptive annihilation trains military personnel as cultural analysts. The stakes are about

$8 \mathrm{UAV}$ - Unmanned aerial vehicle; UCAV - Unmanned combat aerial vehicle. 
schematizing patterns of life, detecting narratives as they appear in visual form and the deviations from those patterns. As one analyst, quoted by Chamayou says, "You're now getting into a culture study. [...] You're looking at people's lives. [...] Essentially, the task consists in distinguishing between 'normal' and 'abnormal' activity in a kind of militarized rhythm-analysis, that takes on increasingly automatized forms" (Chamayou 2011, 43). According to Chamayou, the world has entered into a new stage where surveillance is now a tool not simply for strategic but also for effective annihilation, a process that folds the cultural with the technological, creating an assemblage that radically shifts the cultural organization of the social. The combat-ready drone epitomizes a global eye that has now become a tool to advance preemptive mechanisms of branding, excluding, and annihilating unlivable life. Chamayou considers six major trends in the new surveillance and annihilation culture:

1. The principle or permanent surveillance or permanent watch: freed from the constraints of a human body (that of the pilot) the drone is a resilient and resistant body of iron that enlarges the possibilities of constant 'geo-spatial' overwatch, continuously sending back data to supercomputers, that work to analyze, simplify, and read patterns into it;

2. The principle of the totalization of perspective or synoptic viewing: to see everything, everywhere all the time;

3. The principle of creating an archive of everyone's life: the drone feed is marked by 'archive fever,' as optical surveillance is not limited to present time, but its strength lies precisely in the ability of recording and archiving a myriad of sights that are later built into stories of people's lives. In the drone archive life stories are continuously created and recreated; ${ }^{9}$

4. The principle of data fusion: the feed is multisensory, drones also capture voice communication and data from various devices (computers, mobile phones, etc.). The archival intent is to fuse all of these elements in a common story;

5. The principle of the schematization of forms of life: the data feed provides for a 'cartography of lives,' which has become the epistemic basis of armed surveillance. It is no longer simply about identifying individuals, but of schematically co-creating them;

6. The principle of the detection of anomalies and preemptive anticipation: this is a principle that draws on the cultural competences, on the visual literacy of the analyst and allows for a reading of the present to become a prediction of the future.

9 This happens when the system is perfect: that is, because there is no ability to store, retrieve, and analyze all the data fed by these unmanned vehicles. 
Conflating the post-panopticon's dispersive power, and its total presentness and subsumption into total representation, drone theory speaks to the metamorphic transformations of contemporary surveillance culture. To question the doctrine is, I contend, to question the nature of representation itself. But although the case has been made as to the urgency of understanding how post-panopticon surveillance appropriates cultural literacy for counterinsurgency, the question must be asked: is it simply in diagnosis that the task of the study of culture rests? Arguably, we are not problem-solvers, but no less important or impactful is the task of critique, of understanding, and questioning the perturbations in the normative. Under the spectacularly spectacled conditions of our late modernity, the counter-visuality of sorts we may be able to induce, may come from areas of activity that are not necessarily scholarly, but are certainly objects of scholarly inquiry. Art forms materialize a type of criticality that is increasingly intervening in the public debate, bringing to bear new languages that speak to supplementary modes of knowledge production. Speaking to visually trained audiences, they suggest a mode of representation situated beyond the textual abstraction, on the one hand conveying a new materialism but on the other requiring a sensitive awareness to modes of representation that collapse the traditional device between fact and fiction, authenticity and simulacrum. My final example resorts to art to ask for fault lines in the representation of the drone narrative in what is a widening opportunity to discuss the new and intricate entanglements between real politics, facts, and the imaginary work of artistic creation.

Journalist and director Laura Poitras took surveillance as the node of concern of her exhibition, Astro Noise, which opened at the Whitney Museum in New York City in February 2016. Astro Noise is an installation of the affective assemblages that rule the communal in the post 9/11 world. The visitor is guided through a transformed curatorial space that organizes the experience of living under surveillance around representational modes. In doing so, the viewer is plunged into the landscape of permanent war we live in, and is strategically transformed from detached observer into participant, from being an object of surveillance into an artistic subject.

In the first room of the exhibition space, located on the top floor of the Whitney, two large double screens hang in the middle of the space with video projections to each side of the screen. On the one side, Poitras' short film O'Say Can you See (2001/2011) is projected, featuring onlookers viewing the wreckage of the World Trade Center. Made up of slow-motion reaction shots of by-standers, unwilling observers to the spectacle of destruction, the film creates a sense of separation from reality. As Poitras claims, reaction shots reveal the limits of representation $(2016,36)$; they question the frame and dislocate the hegemony of the seen vis-a-vis the indeterminacy of the seeing. Then, in the background of 
that same screen, the viewer is confronted with footage released by the American military under the Freedom of Information Act, depicting an interrogation of would-be Taliban suspects in Afghanistan in February 2002. American pain and awe are glued to the torture of others, a mutual implication whereby the viewer is instructed to read the visual embedding of what Achille Mbembe calls a necropolitics, a definition of life based on the exercise of control over mortality and as simple deployment and manifestation of power (Mbembe 2003). This is also an invitation to read the impossible representation of the torture of others. Just as the reality of the fallen towers remains outside the frame of the awe-stricken observers, so too does the reality of torture, lie outside the scope of re-presentation.

The visitor then moves to Room 2 and the installation Bed Down Location, where she is invited to lie down in a huge bed looking up at the skies of multiple Middle Eastern cities and New York, just as drone activity is perceived overhead. The skies of Baghdad or Mosul, New York or Kabul appear strikingly alike and yet radically different, pervaded by the fleeting overhead sound of a buzzing engine, a drone, almost imperceptible to viewers. Lying in bed, the visitors are unaware of being recorded by an infrared camera, the feed of which is being streamed live in Room 4. In fact, the whole space of the exhibition is a space of permanent observation, by Poitras' camera, by the military recording, the infrared, and the museum.

Next, the visitor is then guided through a dark corridor with small openings inviting the voyeuristic gaze. Beyond the opening, there are cases with surveillance records, redacted data, pictures, video logs of past Guantánamo prisoners, and writing material. The viewer takes up the position of the gatekeeper in the surveillance system. The objects inside the illuminated cases are visible all together and all the time to the intrusive viewer who remains protected in the dark hall, confronted with the real pain of others. The hall is a transition space, a liminal area that leads up to the transformation of the viewer into object, or rather to the conflation of the viewer-as-object, which takes place in Room 3, as the display of the infrared camera in Room 2 is presented on screen. In the hallway leading out of the installation, this data is equated with a different surveillance product, as viewers visualize the data garnered by UK military satellite surveillance over the Gaza strip. This material is transformed by dint of the aesthetic gesture, blurring the boundaries between art and life, that also speaks to the musealization of surveillance culture.

Poitras' project is about reciprocity, about mutual implication in the project of total war, but it is also a project about the language of the visible and the ways in which citizens, exhibition visitors, artists, scholars, and activists are led to operate within this "surveillant assemblage" (Weizman 2017). Ultimately it is also a project about storytelling, about creating narratives that model social and polit- 
ical constellations. In the age of the post-panopticon, Poitras invites the surveyed to understand emotionally, disbanding the categories between viewer and the viewed and stressing the mutual vulnerability that is the trademark of this new stage of the social.

In an interview, Poitras claims this is an exhibition that turns the museum viewer into the protagonist and forces her to make choices. Insomuch as it reproduces the conditions that place individuals under the global eye of surveillance, art acts out a paradoxical role that replicates the circumstances of control just as it produces critique, or an artistic criticality in Irit Rogoff's sense (Rogoff 2003), ${ }^{10}$ that is, a critique embedded in the position of the artist as a situated body in a constellation of mutually engaged relations. Poitras states: "I am interested not just in the experience of the viewer as protagonist moving through a narrative journey but in how other bodies create that narrative experience" (Poitras 2016, 33). This is a project for a new communality, a call for recognition and engagement enacted through art. It is a project conflating the educated position of critique with the artistic edge of creation, a model of collaboration in knowledge, and a critical act to traverse the complexity of our present.

\section{Coda}

While the metaphor of sight as a model of cultural engagement has prevailed in Western aesthetics from Aristotle to Nicolas of Cusa, and from myth to science and art, the liquid condition of the twenty-first century has brought on radical changes. A top-down hierarchical dispositif structured upon the exercise of discipline over docile bodies, the panoptical model devised by Jeremy Bentham and revised by Michel Foucault turned vision into a strategy of domination and power, a simultaneously creative and repressive mechanism producing docile subjectivities held together by the institutional power of the disciplinary apparatus. In the post-panoptical world of pervasive seeing-inducing technology, where everyone is watching and being watched, the visible has become the locus of a new cultural model that is no longer set on discipline but on surveillance; on organizing

10 Rogoff defines the move from critique to criticality as a motion of productive engagement, moving from blame to power, that is: "[...]from finding fault, to examining the underlying assumptions that might allow something to appear as a convincing logic, to operating from an uncertain ground which while building on critique wants nevertheless to inhabit culture in a relation other than one of critical analysis; other than one of illuminating flaws, locating elisions, allocating blames, “ Rogoff 2003, xx. 
areas of observed participation, of shaping questions and monitoring answers; and on devising the problems, the bodies, and the institutions that organize the social. A metadiscipline that works across contextual deployment by analyzing phenomena and, as Siegfried Kracauer put it, its "surface-level expressions" (Kracauer 1988, 75), the study of culture has consistently addressed the multiple ways in which the changes of the post-panoptical world infiltrate and shape cultural experience, as well as how art and culture can work to resist these oblique powers and produce new modes of seeing the world. Surveillance studies and the meaning-inducing strategies that are at work in the world of total visuality shape a field of inquiry that requires a transdisciplinary approach, an understanding of contextual hermeneutics and mediation as well as the narratological tools to unpack the identitarian storytelling secretly conducted in and through surveillance. Questions most likely to inform the wider undertaking ask: what does the new surveillance do to the understanding of the human? How does it affect subjectivity and artistic creation? What are the tools used to infiltrate the organization of the sensible? In the world of total visuality, can there be an outside to cultural models produced and enacted within the limits of surveillance? And what are the new languages that produce this outside? Because, as always, the work of culture will likely be the strategic opening at the beginning of resistance.

\section{References}

Appadurai, Arjun. Fear of Small Numbers. Durham, NC: Duke University Press, 2006.

Aristotle. The Metaphysics. Trans. Hugh Lawson-Tancred. Harmondsworth: Penguin, 1999.

Azoulay, Ariella. The Civil Contract of Photography. Cambridge, MA: Zone Books, 2008.

Baudrillard, Jean. Simulacra and Simulation. Ann Arbor: University of Michigan Press, 1994.

Bauman, Zygmunt, and David Lyon. Liquid Surveillance: A Conversation. Cambridge/Malden,

MA: Polity, 2013.

Bigo, Didier. "Security: A Field Left Fallow." Foucault on Politics, Security and War. Eds. Michael

Dillon and Andrew W. Neal. Basingstoke/New York: Palgrave Macmillan, 2011. 100-110.

Carpenter, Humphrey, ed. The Letters of JRR Tolkien. New York: Houghton Milffin, 1981.

Cavarero, Adriana. For More Than One Voice: Toward a Philosophy of Vocal Expression.

Stanford: Stanford University Press, 2005.

Chamayou, Grégoire. Drone Theory. New York: Penguin, 2011.

Conty, Arianne. "Absolute Art: Nicholas of Cusa's De Visione Dei." Religion and the Arts

16 (2012): 461-487.

Crary, Jonathan. Suspensions of Perception: Attention, Spectacle and Modern Culture.

Cambridge, MA: MIT Press, 1999.

Cusa, Nicholas of. Visions of God. Boston: Book Tree, 1999.

Foucault, Michel. Discipline and Punish: The Birth of the Prison. New York: Vintage Books, 1995. 
Gil, Isabel Capeloa. Mitografias: Figurações de Antígona, Cassandra e Medeia no Drama de Expressão Alemã do Século XX. Lisboa: INCM, 2007.

Grossberg, Lawrence. Cultural Studies in the Future Tense. Durham, NC/London: Duke University Press, 2010.

Grusin, Richard. Premediation: Affect and Mediality After 9/11. Basingstoke/New York: Palgrave Macmillan, 2010.

Harari, Yuval Noah. 21 Lessons for the 21st Century. New York: Random House, 2018.

Kracauer, Siegfried. The Mass Ornament. Cambridge, MA: Harvard University Press, 1988.

Lyon, David. The Electronic Eye: The Rise of Surveillance Society. Cambridge: Polity, 1994.

Lyon, David. Surveillance Society: Monitoring Everyday Life. Buckingham/Philadelphia: Open University Press, 2001.

Lyon, David. "9/11, Synopticon, and Scopophilia: Watching and Being Watched." The New Politics of Surveillance and Visibility. Eds. Kevin D. Haggerty and Richard

V. Ericson. Toronto: University of Toronto Press, 2006. 35-54.

Mbembe, Achille. “Necropolitics.” Public Culture 15.1 (2003): 11-40.

Mirzoeff, Nicholas. How to See the World. London: Pelican, 2015.

Mozur, Paul. “Inside China's Dystopian Dreams: A.I., Shame and Lots of Cameras.” The New York Times (8 July 2018). https://www.nytimes.com/2018/07/08/business/ china-surveillance-technology.html [accessed: 25 January 2019].

Poitras, Laura. Astro Noise: A Survival Guide for Living Under Total Surveillance. New York: Whitney Museum, 2016.

Rogoff, Irit. "What is a Theorist.” Was ist ein Künstler? Eds. Katharina Sykora et al. Berlin: Transvia, 2003.

Scott, James C. Seeing Like a State: How Certain Schemes to Improve the Human Condition Have Failed. New Haven: Yale University Press, 1998.

Staples, William G. The Culture of Surveillance: Discipline and Social Control in the United States. New York: St. Martin's Press, 1997.

Turkle, Sherry. Simulation and Its Discontents. Cambridge, MA: MIT Press, 2009.

Vernant, Jean-Pierre. "Die religiöse Erfahrung der Andersheit. Das Gorgogesicht." Faszination des Mythos. Studien zu antiken und modernen Interpretationen. Ed. Renate Schlesier. Basel: Stroemfeld/Roter Stern, 1985. 399-420.

Virilio, Paul. War and Cinema: The Logistics of Perception. London/New York: Verso, 2009.

Weizman, Eyal. Forensic Architecture: Violence at the Threshold of Detectability. Cambridge, MA: Zone Books, 2017.

Williams, Raymond. The Long Revolution. Harmondsworth: Penguin, 1961. 


\section{ANNEX}

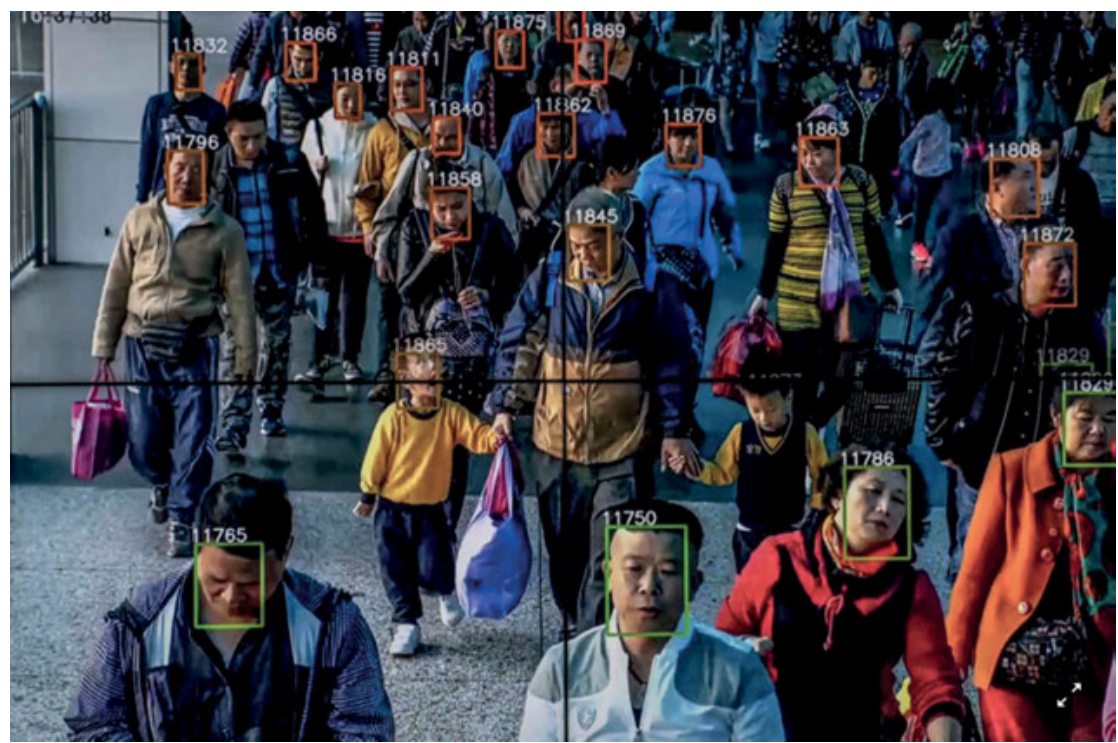

Fig. 1: A video showing facial recognition at Megvii intelligence company in Beijing. Credits: Gilles Sabrie New York Times (published July 8, 2018).

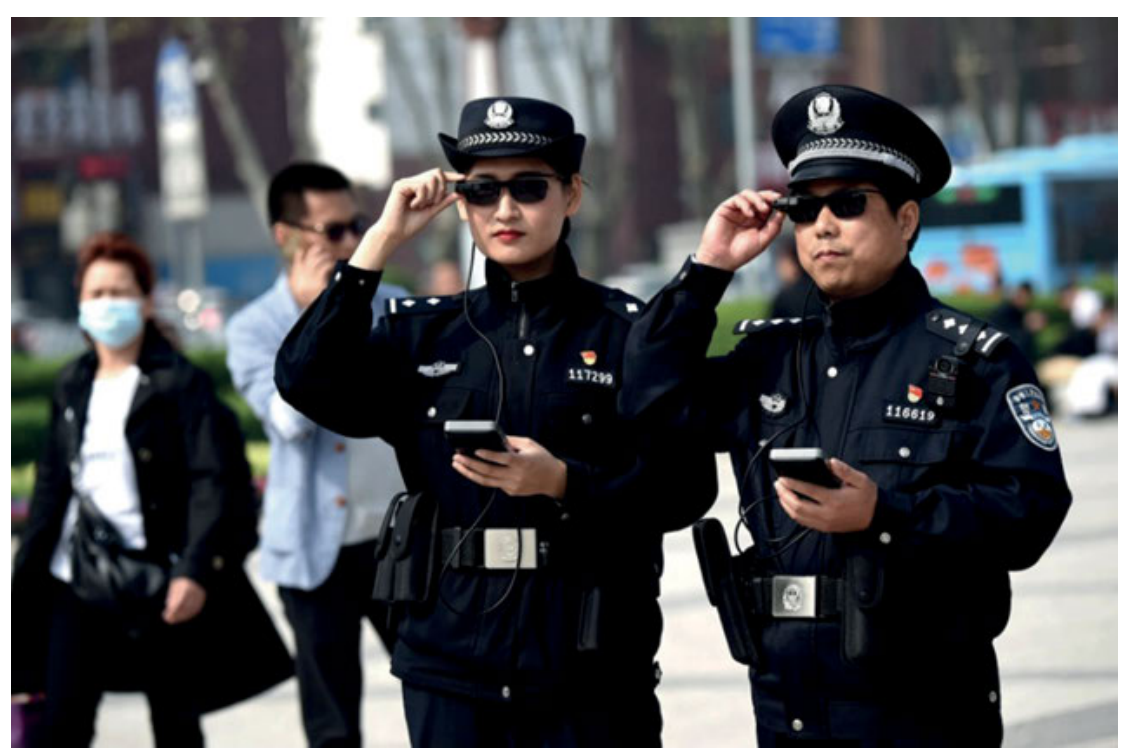

Fig. 2: Chinese Police wearing A.I.-powered smartglasses. Credits: Reuters. 


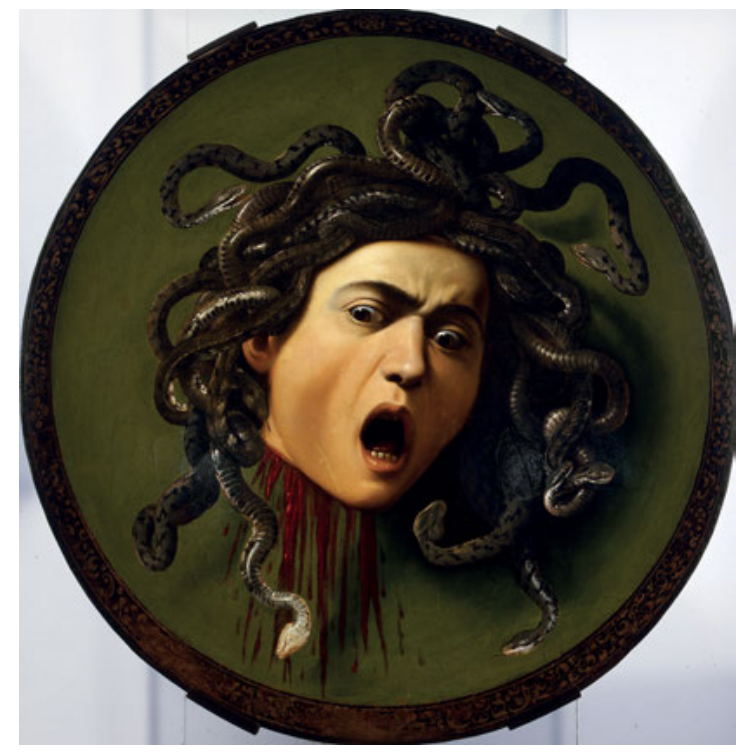

Fig. 3: Michelangelo Merisi da Caravaggio, Medusa (1597). Le Gallerie degli Uffizi, Florence. 